\title{
A cross-sectional study to evaluate second line virological failure and elevated bilirubin as a surrogate for adherence to atazanavir/ritonavir in two urban HIV clinics in Lilongwe, Malawi
}

Dennis Miyoge Ongubo ${ }^{1}$, Robertino Lim², Hannock Tweya ${ }^{3,4}$, Christopher Chikhosi Stanley ${ }^{5}$, Petros Tembo ${ }^{3}$, Richard Broadhurst ${ }^{6}$, Salem Gugsa ${ }^{3}$, McNeil Ngongondo ${ }^{5}$, Colin Speight ${ }^{3}$, Tom Heller ${ }^{3}$, Sam Phiri ${ }^{3,6,7}$

and Mina C. Hosseinipour ${ }^{5,6^{*}}$ (D)

\begin{abstract}
Background: Malawi's national antiretroviral therapy program provides atazanavir/ritonavir-based second line regimens which cause concentration-dependent rise in indirect bilirubin. We sought to determine if elevated bilirubin, as a surrogate of atazanavir/ritonavir adherence, can aid in the evaluation of second line virological failure in Malawi.

Methods: We conducted a cross-sectional study of HIV-infected patients $\geq 15$ years who were on boosted protease inhibitor-based second line antiretroviral therapy for at least 6 months in two urban HIV clinics in Lilongwe, Malawi. Antiretroviral therapy history and adherence data were extracted from the electronic medical records and blood was drawn for viral load, complete blood count, total bilirubin, and CD4 cell count at a clinic visit. Factors associated with virological failure were assessed using multivariate logistic regression model.
\end{abstract}

Results: Out of 376 patients on second line antiretroviral therapy evaluated, 372 (98.9\%) were on atazanavir/ritonavirbased therapy and 142 (37.8\%) were male. Mean age was 40.9 years (SD \pm 10.1$)$, mean duration on second line antiretroviral therapy was 41.9 months (SD \pm 27.6 ) and 256 patients (68.1\%) had elevated bilirubin $>1.3 \mathrm{mg} / \mathrm{dL}$. Overall, 35 (9.3\%) patients had viral load $>1000$ copies/ml (virological failure). Among the virologically failing vs. non-failing patients, bilirubin was elevated in $34.3 \%$ vs. $72.0 \%$ respectively $(p<0.001)$, although adherence by pill count was similar $(62.9 \%$ vs. $60.7 \%, p=0.804)$. The odds of virological failure were higher for adults aged $25-40$ years (adjusted odds ratio (aOR) 2.5, $p=0.048$ ), those with CD4 cell count $<100$ (aOR 17.5, $p<0.001$ ), and those with normal bilirubin levels (aOR $5.4, p<0.001$ ); but were lower for the overweight/obese patients (aOR 0.3, $p=0.026$ ). Poor pill count adherence (aOR $0.7, p=0.4$ ) and male gender (aOR 1.2, $p=0.698$ ) were not associated with second line virological failure.

Conclusions: Among patients receiving atazanavir/ritonavir-based second line antiretroviral therapy, bilirubin levels better predicted virological failure than pill count adherence. Therefore, strategic use of bilirubin and viral load testing to target adherence counseling and support may be cost-effective in monitoring second line antiretroviral therapy adherence and virological failure. Drug resistance testing targeted for patients with virological failure despite elevated bilirubin levels would facilitate timely switch to third line antiretroviral regimens whenever available.

Keywords: Virological failure, Atazanavir/ritonavir, Second line, Antiretroviral therapy, Bilirubin, Adherence, Surrogate

\footnotetext{
* Correspondence: mina_hosseinipour@med.unc.edu

${ }^{5}$ University of North Carolina Project, Lilongwe, Malawi

${ }^{6}$ University of North Carolina School of Medicine, Chapel Hill, USA

Full list of author information is available at the end of the article
} 


\section{Background}

Antiretroviral therapy (ART) scale-up in developing countries reversed upward trends in HIV-associated mortality, morbidity, and disease transmission (http://www.unaids.org/sites/default/files/country/documents/MWI_narrative _report_2015.pdf). Despite these improved outcomes in many patients on ART, some eventually fail first line and second line treatment resulting in increased morbidity and mortality for people living with HIV (PLHIV) [1, 2]. Monitoring of treatment adherence and treatment failure is a challenge (http://www.who.int/hiv/pub/arv/adult2010/en/; http://www.who.int/hiv/topics/treatment/First_Line_ART_failure_RLS_metanalysis.pdf [3]), particularly due to the limited access to viral load testing and genotyping assays [4, 5]. Poor adherence to first line ART often translates to continued poor adherence to later lines of ART [6, 7]. While drug resistance contributes to second line virological failure (VF) [8], poor adherence, often in the absence of drug resistance has been described [9-13]. Therefore, detection of poor adherence to ART accompanied by targeted adherence counseling and support may lead to better virological suppression and lower ART switch rates [14, 15].

Approximately 1\% of patients in Malawi's national ART program were on second line regimens with the majority (91\%) assessed as adherent based on indirect medication adherence measurements such as pill count and selfreported missed doses (http://www.unaids.org/sites/default/ files/country/documents/MWI_narrative_report_2015.pdf). Malawi adopted atazanavir/ritonavir (ATV/r) as the boosted protease inhibitor (PI/r) of choice in 2013; this being a switch from lopinavir/ritonavir (LPV/r) used earlier in its second line ART regimens [16]. ATV/r causes a dosedependent indirect hyperbilirubinemia [17-21]. This biologic phenomenon has the potential, as an inexpensive surrogate measure of adherence to an ATV/r regimen [22], to distinguish between non-adherence and drug resistance as the cause for VF of second line ART regimens.

There is currently limited data describing both second line VF and whether ATV/r-associated hyperbilirubinemia might serve as a biologic marker of treatment adherence. We, therefore, sought to determine the prevalence and understand the factors associated with VF in a cohort of HIV-infected ART-experienced Malawians on second line ART. We also sought to evaluate the role of serum total bilirubin as a surrogate marker for ATV/r adherence.

\section{Methods}

\section{Study setting}

This study was conducted at Lighthouse (LH) and Martin Preuss Centre (MPC) outpatient HIV clinics in Lilongwe, Malawi. The Lighthouse Trust, operating both LH clinic and MPC, is the largest provider of adult HIV care for PLHIV in Malawi. The integrated Tuberculosis(TB)/HIV care program and Option $\mathrm{B}+$ program for $\mathrm{HIV}$ positive pregnant and breastfeeding women and their families is based at MPC, while all other services are provided at both sites. Viral load (VL) monitoring is done according to Malawi's national ART guidelines at 6 months following initiation of a new ART regimen and at 2 years and every 2 years thereafter [16]. First line ART is tenofovir/lamivudine/efavirenz (TDF/3TC/EFV); referred to within the Malawi National ART Program as $5 \mathrm{~A}$ ) with the potential use of nevirapine (NVP), abacavir/lamivudine (ABC/3TC) or zidovudine/lamivudine (AZT/3TC) for toxicity management ([16], http://www.who.int/hiv/pub/guidelines/ arv2013/download/en/). Second line ART is AZT/3TC or TDF/3TC plus ATV/r. Lopinavir/ritonavir (LPV/r) is available as a substitute for ATV/r's toxicity or when TB treatment is required ([16], http://www.who.int/hiv/pub/ guidelines/arv2013/download/en/).

\section{Study population and design}

Study participants were identified from the clinics' Electronic Medical Records (EMR) systems. They included HIV-infected patients aged $\geq 15$ years attending the MPC and LH outpatient HIV clinics who were receiving PI/rbased second line ART for at least 6 months and with HIV1 RNA (VL) results. At their regularly scheduled outpatient visits between December 2013 and May 2014, blood was collected for VL, complete blood count (CBC), CD4 cell count, renal function tests and liver panel. We then conducted a cross-sectional study of these participants to assess the factors associated with second line VF within these two facilities. At the time of evaluation, it was estimated that approximately 400 individuals had been initiated on second line therapy in Lighthouse clinics (approximately $2 \%$ of the Lighthouse ART population). This proportion is slightly higher than the national average ( $1 \%$ of the national ART population) because Lighthouse, as a center of excellence, serves as a referral centre as well as one of the first and largest providers of ART services in the country.

\section{Sources of data}

All HIV-infected individuals receiving care at $\mathrm{LH}$ and MPC were registered in the EMR systems, as described previously ([23], https://github.com/openmrs), where detailed patients' records collected were accessible through printed reports or directly via the touchscreen terminals in the reception and clinical consultation rooms. These systems also guided the healthcare workers according to Malawi's clinical HIV guidelines and facilitated medication prescribing and dispensing while performing clinical calculations (e.g., drug adherences). For this study, socio-demographic, clinical and laboratory data, body weight, ART treatment history and previous trends in antiretroviral drug adherence (through pill counts) for individuals on second line ART were obtained from the EMR systems and patients' medical charts. 


\section{Laboratory evaluations}

All the blood samples were processed at the University of North Carolina Research Project Laboratory in Lilongwe. VL was measured using the Abbott Real Time HIV-1 assay system (https://www.abbottmolecular.com/us/products/realtime-hiv-1.html). CD4 cell counts were determined by flow cytometry using the Becton Dickinson FACSCount system (Becton Dickinson, Mountain View, California, USA). Complete blood count (CBC) was analyzed in the Beckman Coulter AcT 5diff Cap Pierce hematology analyzer (Beckman Coulter, Miami, FL), while liver and renal function tests were analyzed in the Roche Cobas C 311 chemistry analyzer. Laboratory results were graded according to the National Institute of Health Division of AIDS (DAIDS) Tables for grading the severity of adult and pediatric adverse events: Version 2.0 - November 2014 (http://rsc.tech-res.com/Document/safetyandpharmacovigilance/DAIDS_AE_GRADING_TABLE_v2_ NOV2014.pdf).

\section{Variables}

The primary outcome was the proportion of patients on second line PI/r-based ART with virological failure (VF) defined as VL $>1000$ copies/ml per Malawi's guidelines [16] based on a single blood draw regardless of reported pill count adherence. The primary predictor variable was the cumulative $\mathrm{PI} / \mathrm{r}$ pill count adherence, whenever possible, which is the average $\mathrm{PI} / \mathrm{r}$ pill count adherence for at least 6 months prior to the VL sample collection date. This is calculated as:

(pill adherence $)=($ pill sum difference $) /($ pill use interval $)$, where;

$$
\begin{aligned}
& >\text { Pill sum difference }=(\text { previous pill sum })-(\text { current } \\
& \text { pill count }) \\
& >\text { Previous pill sum }=(\text { pill count prior to supply } \\
& \text { visit })+(\text { pills dispensed at supply visit }) \\
& >\text { Pill use interval }=(\text { no. of days used pills since last } \\
& \text { supply) X (number of PI/r pills taken per day) }
\end{aligned}
$$

We defined good adherence for desirable virological outcome (VL $\leq 1000$ copies $/ \mathrm{ml}$ ) in this study as average pill count adherence of $\geq 95 \%$ and $\leq 105 \%$ [24]. The other variables of interest included age, gender, body mass index (BMI), CD4 cell count, total bilirubin, duration on $\mathrm{ART}$, duration on second line ART, PI/r base, and nucleoside reverse transcriptase inhibitor (NRTI) backbone. All study participants analyzed had VL measurements for determination of VF. We also used a VL threshold of 400 copies $/ \mathrm{ml}$ to calculate the prevalence rate of VF for comparison to other studies.

\section{Statistical analysis}

Descriptive statistics were used to summarize the study population characteristics and the overall prevalence of second line VF. Continuous variables were summarized using mean and standard deviation (SD); categorical variables were summarized using frequency and percent (\%). The distribution of viral load measurement in our study sample was non-normal due to the high proportion of individuals that were successfully suppressed. Other variables were normally distributed. Associations between socio-demographic or HIV-related variables and VF were assessed using the $\chi^{2}$ test for categorical variables and the Student's $t$-test for continuous variables. We used univariate logistic regression analysis to identify factors associated with VF, in addition to the known determinants of VF $[25,26]$. Sensitivity, specificity, positive and negative predictive values using bilirubin testing to screen for VF were also calculated. We then used a multivariate logistic regression model fitted through backward selection of variables to assess the adjusted effect of predictor variables on the primary outcome (VF). Age, gender, pill count adherence and time on ART were included a priori to the model. Variance inflation factors were computed for each of the predictor variable to exclude from the model covariates that demonstrated collinearity. All analyses were done in STATA SE version 12.0 (College Station, Texas). Statistical significance was considered at a two-sided $\alpha$-level of 0.05 .

\section{Results}

Out of 376 HIV-infected patients on second line ART evaluated, $372(98.9 \%)$ were on ATV/r-based therapy at the time of study and $142(37.8 \%)$ were male (Table 1). The mean age was 40.9 years $(\mathrm{SD} \pm 10.1)$, the mean duration on second line ART was 41.9 months $(\mathrm{SD} \pm 27.6)$, and the mean duration on ATV/r-based second line therapy was 9.1 months (SD \pm 1.5 ). Two hundred and twenty nine (60.9\%) patients appeared to have averaged good adherence by pill count over the previous 6 months while $256(68.1 \%)$ patients had elevated bilirubin ( $>1.3 \mathrm{mg} / \mathrm{dL})$. Of the 376 individuals with VL data, 35 (9.3\%) had VL > 1000 copies/ml, 37 (9.8\%) had VL $\geq 400$ copies/ml while 93 (24.7\%) had VL $\geq 40$ copies $/ \mathrm{ml}$.

Overall, out of 35 (9.3\%) patients who had Malawidefined VF (VL > 1000 copies $/ \mathrm{ml}$ ) while on second line ART (Table 2 ), the majority (60\%) were aged $25-40$ years old in these two urban HIV clinics. Among the virologically failing vs. non-failing patients, those failing therapy were younger (mean age of 36 vs. 41.4 years, $p=0.0025$ ), had lower CD4 cell count (mean of 206 vs. 466 cells $/ \mathrm{mm}^{3}$, $p<0.001)$, and had significantly lower bilirubin levels $(1.0$ vs. $2.4 \mathrm{mg} / \mathrm{dL}, p<0.001)$. Bilirubin was elevated in $34.3 \%$ vs. $72.0 \%$ respectively $(p<0.001)$, although adherence by pill count were similar $(62.9 \%$ vs. $60.7 \%, p=0.804)$. The distributions of other population characteristics were similar among the virologically failing vs. non-failing patients. We observed medium correlation between VF and World 
Table 1 Population characteristics of HIV-infected patients on second line ART in two urban HIV clinics in Lilongwe, Malawi

\begin{tabular}{|c|c|}
\hline Characteristics (Categorical) & $\begin{array}{l}N=376 \\
n(\%)\end{array}$ \\
\hline \multicolumn{2}{|l|}{ Age in years } \\
\hline $15-24$ & $27(7.2)$ \\
\hline $25-40$ & $161(42.8)$ \\
\hline$>40$ & $188(50.0)$ \\
\hline \multicolumn{2}{|l|}{ Gender } \\
\hline female & $234(62.2)$ \\
\hline male & $142(37.8)$ \\
\hline \multicolumn{2}{|l|}{ CD4 cell count (cells/mm³) } \\
\hline$\geq 100$ & $362(96.3)$ \\
\hline$<100$ & $12(3.2)$ \\
\hline \multicolumn{2}{|l|}{ Virological failure (>1000 copies/ml) } \\
\hline yes & $35(9.3)$ \\
\hline no & $341(90.7)$ \\
\hline \multicolumn{2}{|l|}{$\mathrm{BMI}\left(\mathrm{kg} / \mathrm{m}^{2}\right)$} \\
\hline normal & $207(55.1)$ \\
\hline underweight & $25(6.7)$ \\
\hline overweight/obese & $144(38.3)$ \\
\hline \multicolumn{2}{|l|}{ Pill count adherence } \\
\hline $\operatorname{good}(95 \%-105 \%)$ & $229(60.9)$ \\
\hline poor $(<95 \%$ or $>105 \%)$ & $147(39.1)$ \\
\hline \multicolumn{2}{|l|}{ Current boosted protease inhibitor } \\
\hline atazanavir/ritonavir & $372(98.9)$ \\
\hline lopinavir/ritonavir & $4(1.1)$ \\
\hline \multicolumn{2}{|l|}{ Current NRTI backbone } \\
\hline $\mathrm{ABC} / 3 \mathrm{TC}$ & $5(1.3)$ \\
\hline AZT/3TC & $67(17.8)$ \\
\hline TDF/3TC & $303(80.6)$ \\
\hline $\mathrm{d} 4 \mathrm{~T} / 3 \mathrm{TC}$ & $1(0.3)$ \\
\hline \multicolumn{2}{|l|}{ Reason for ART initiation } \\
\hline WHO clinical stage III/IV & $283(75.3)$ \\
\hline CD4 cell count below threshold & $74(19.7)$ \\
\hline pregnancy/lactating & $3(0.8)$ \\
\hline \multicolumn{2}{|l|}{ Total bilirubin level } \\
\hline elevated (>1.3 mg/dL) & $256(68.1)$ \\
\hline normal ( $\leq 1.3 \mathrm{mg} / \mathrm{dL})$ & $118(31.4)$ \\
\hline \multirow[t]{2}{*}{ Characteristics (Continuous) } & $N=376$ \\
\hline & Mean (SD) \\
\hline age (years) & $40.9(10.1)$ \\
\hline CD4 cell count (cells/mm³) & $442.6(245.8)$ \\
\hline time on ART (months) & $89.9(34.4)$ \\
\hline time on second line ART (months) & $41.9(27.6)$ \\
\hline time on ATV/r base (months) & $9.1(1.5)$ \\
\hline BMI $\left(\mathrm{kg} / \mathrm{m}^{2}\right)$ & $24.7(5.0)$ \\
\hline total bilirubin (mg/dL) & $2.2(1.6)$ \\
\hline hemoglobin ( $\mathrm{g} / \mathrm{dL}$ ) & $12.9(2.1)$ \\
\hline
\end{tabular}

Numbers and proportions may not add up due to missing data
Health Organization (WHO) defined immunological failure $\left(\mathrm{CD} 4\right.$ cell count $<100$ cells $\left./ \mathrm{mm}^{3}\right)(r=0.3119, p$-value $<0.001)$.

The sensitivity and specificity of using bilirubin testing at the $1.3 \mathrm{mg} / \mathrm{dL}$ level to screen for VF was $65.7 \%$ and $72 \%$ respectively with a false negative rate of $34.3 \%$ and false positive rate of $28 \%$. Bilirubin testing had a negative predictive value (NPV) of $95.3 \%$ and a positive predictive value (PPV) of $19.5 \%$. The positive likelihood ratio (PLR) was 2.3 while the negative likelihood ratio (NLR) was 0.5 . Using higher bilirubin cutpoints increased sensitivity but reduced specificity (Table 3).

Univariate and multivariate logistic regressions identified factors associated with VF (Table 4). The odds of VF were higher for adults aged 25-40 years (adjusted Odds Ratio (aOR) $2.5, p=0.048$ ), those with CD4 cell count $<100$ cells/ $\mathrm{mm}^{3}$ (aOR 17.5, $p<0.001$ ), and those with normal bilirubin levels (aOR 5.4, $p<0.001$ ); but were lower for the overweight/obese patients (aOR 0.3, $p=0.026)$. Poor adherence by pill count (aOR $0.7, p=0.4$ ) and male gender (aOR 1.2, $p=0.698$ ) were not associated with increased risk of VF. Similarly, time on second line ART (aOR $1 ; p=0.921)$ and time on ATV/r (aOR 0.9; $p=0.409$ ) were not associated with increased risk of VF and did not demonstrate collinearity. Additionally, using bilirubin as a continuous variable, the odds of VF were 0.31 less for every unit rise in total bilirubin $(p$-value $<0.005)$.

\section{Discussion}

We found a surprisingly low prevalence rate of VF (9.3\%) among patients retained on second line ART at these two urban outpatient HIV clinics in Lilongwe, Malawi. Importantly, we identified several easily measureable factors predicting VF including bilirubin levels, CD4 cell count, BMI and age. Bilirubin testing, as a biologic marker for adherence to ATV/r-based therapy, may be an effective tool in evaluating patients for ART adherence and VF prior to the more expensive and less available genotype resistance testing and third line therapy.

The prevalence rate of second line VF was lower in this study than reported elsewhere [10], although different VL thresholds were used to make the comparison. We used a VL threshold of 1000 copies/ml to define VF to align to Malawi's guidelines whereas other studies $[2,27]$ used a lower VL threshold of 400 copies/ml to define failure. Despite the sensitivity of VF rates to VL thresholds for failure definition [27], our study yielded low rates of $9.8 \%$ for VL thresholds of 400 copies $/ \mathrm{ml}$. ATV/r which is dosed once daily may have fewer side effects than LPV/r, and this may favor better treatment adherence and virological suppression as evidenced in this study [16, 28]. Previous studies that reported higher rates of VF predominantly used LPV/r as the PI/r of choice $[10,29]$. However, we do not expect differences in therapeutic responses to $\mathrm{LPV} / \mathrm{r}$ 
Table 2 Characteristics of HIV-infected patients with second line virological failure in two urban HIV clinics in Lilongwe, Malawi

\begin{tabular}{|c|c|c|c|c|}
\hline Characteristics (Categorical) & $\begin{array}{l}\text { Viral load } \leq 1000 \\
N=341 \\
n(\text { column\%) }\end{array}$ & $\begin{array}{l}\text { Viral load > } 1000 \\
N=35 \\
n(\text { column\%) }\end{array}$ & $\begin{array}{l}\text { Total } \\
N=376 \\
n(\text { column\%) }\end{array}$ & $p$-value \\
\hline \multicolumn{5}{|l|}{ Age in years } \\
\hline $15-24$ & $22(6.5)$ & $5(14.3)$ & $27(7.2)$ & \\
\hline $25-40$ & $140(41.1)$ & $21(60.0)$ & $161(42.8)$ & \\
\hline$>40$ & $179(52.5)$ & $9(25.7)$ & $188(50.0)$ & $0.005^{*}$ \\
\hline \multicolumn{5}{|l|}{ Gender } \\
\hline female & $212(62.2)$ & $22(62.9)$ & $234(62.2)$ & \\
\hline male & $129(37.8)$ & $13(37.1)$ & $142(37.8)$ & 0.936 \\
\hline \multicolumn{5}{|l|}{ CD4 cell count (cells/mm³) } \\
\hline$\geq 100$ & $335(98.5)$ & $27(79.4)$ & $362(96.8)$ & \\
\hline$<100$ & $5(1.5)$ & 7 (20.6) & $12(3.2)$ & $<0.001^{*}$ \\
\hline \multicolumn{5}{|l|}{ BMI $\left(\mathrm{kg} / \mathrm{m}^{2}\right)$} \\
\hline normal & $183(53.7)$ & 24 (68.6) & $207(55.1)$ & \\
\hline underweight & $21(6.2)$ & $4(11.4)$ & $25(6.7)$ & \\
\hline overweight/obese & $137(40.1)$ & $7(20)$ & $144(38.3)$ & $0.031^{*}$ \\
\hline \multicolumn{5}{|l|}{ Pill count adherence } \\
\hline $\operatorname{good}(95 \%-105 \%)$ & $207(60.7)$ & $22(62.9)$ & $229(60.9)$ & \\
\hline poor $(<95 \%$ or $>105 \%)$ & $134(39.3)$ & $13(37.1)$ & $147(39.1)$ & 0.804 \\
\hline \multicolumn{5}{|l|}{ Current boosted protease inhibitor } \\
\hline atazanavir/ritonavir & $338(99.1)$ & $34(97.1)$ & $372(98.9)$ & \\
\hline lopinavir/ritonavir & $3(0.9)$ & $1(2.9)$ & $4(1.1)$ & $0.325^{*}$ \\
\hline \multicolumn{5}{|l|}{ Current NRTI backbone } \\
\hline $\mathrm{ABC} / 3 \mathrm{TC}$ & $4(1.2)$ & $1(2.9)$ & $5(1.3)$ & \\
\hline AZT/3TC & $61(17.9)$ & $6(17.1)$ & $67(17.8)$ & \\
\hline TDF/3TC & $275(80.7)$ & $28(80)$ & $303(80.6)$ & \\
\hline $\mathrm{d} 4 \mathrm{~T} / 3 \mathrm{TC}$ & $1(0.3)$ & $0(0)$ & $1(0.3)$ & $0.583^{*}$ \\
\hline \multicolumn{5}{|l|}{ Reason for ART initiation } \\
\hline WHO clinical stage III/IV & $254(77.9)$ & $29(85.3)$ & $283(78.6)$ & \\
\hline CD4 count below threshold & $69(21.2)$ & $5(14.7)$ & $74(20.6)$ & \\
\hline pregnancy/lactating & $3(0.9)$ & $0(0)$ & $3(0.8)$ & $0.633^{*}$ \\
\hline \multicolumn{5}{|l|}{ Total bilirubin level } \\
\hline elevated (>1.3 mg/dL) & $244(72.0)$ & $12(34.3)$ & $256(68.5)$ & \\
\hline normal ( $\leq 1.3 \mathrm{mg} / \mathrm{dL})$ & $95(28.0)$ & $23(65.7)$ & $118(31.6)$ & $<0.001$ \\
\hline \multirow[t]{2}{*}{ Characteristics (Continuous) } & Viral Load $\leq 1000$ & Viral Load > 1000 & & $p$-value \\
\hline & Mean (SD) & Mean (SD) & Total & \\
\hline age (years) & $41.4(10.0)$ & $36.0(9.5)$ & 376 & 0.0025 \\
\hline CD4 cell count (cells/mm³) & $466.3(241.2)$ & $205.6(146.5)$ & 374 & $<0.001$ \\
\hline time on ART (months) & $90.1(34.9)$ & $88.5(29.4)$ & 372 & 0.795 \\
\hline time on second line ART (months) & $42.5(27.7)$ & $35.5(25.9)$ & 376 & 0.1516 \\
\hline time on ATV/r base (months) & $9.1(1.5)$ & $9.0(1.8)$ & 372 & 0.7069 \\
\hline BMI $\left(\mathrm{kg} / \mathrm{m}^{2}\right)$ & $24.9(5.1)$ & $23.2(4.7)$ & 376 & 0.0516 \\
\hline total bilirubin (mg/dL) & $2.4(1.6)$ & $1.0(1.1)$ & 374 & $<0.001$ \\
\hline hemoglobin (g/dL) & $13(2.1)$ & $12.1(1.5)$ & 376 & 0.0144 \\
\hline
\end{tabular}


Table 3 Association of different bilirubin cut-off levels with second line virological failure

\begin{tabular}{lllll}
\hline Bilirubin levels* & Sensitivity & Specificity & Positive Predictive Value & Negative Predictive Value \\
\hline 1.3 (Lab Upper Limit of Normal) & 65.7 & 72 & 19.5 & 95.3 \\
$<2.08$ (DAIDS Toxicity Grade $<=1$ ) & 85.7 & 49.9 & 15 & 97.1 \\
$<3.38$ (DAIDS Toxicity Grade $<=2)$ & 94.3 & 20.1 & 10.9 & 97.1 \\
$<6.5$ (DAIDS Toxicity Grade $<=3$ ) & 100 & 3.24 & 9.6 & 100
\end{tabular}

*Bilirubin values above represent the cut-offs corresponding with DAIDS Version 2.0 toxicity reporting requirements

Table 4 Factors associated with second line virological failure in two urban HIV clinics in Lilongwe, Malawi

\begin{tabular}{|c|c|c|c|c|}
\hline \multirow[b]{2}{*}{ Characteristics } & \multicolumn{2}{|l|}{ Un-adjusted } & \multicolumn{2}{|l|}{ Adjusted } \\
\hline & Odds Ratios & $p$-value & Odds Ratios & $p$-value \\
\hline \multicolumn{5}{|l|}{ Age in years (at time of study evaluation) } \\
\hline$>40$ & Referent & & & \\
\hline $25-40$ & 3 & 0.008 & 2.5 & 0.048 \\
\hline $15-24$ & 4.5 & 0.012 & 1.5 & 0.611 \\
\hline age, per each additional year & 0.9 & 0.003 & & \\
\hline age at second line ART initiation, per additional year & $<1.0$ & 0.008 & & \\
\hline \multicolumn{5}{|l|}{ Gender } \\
\hline female & Referent & & & \\
\hline male & $<1.0$ & 0.936 & 1.2 & 0.698 \\
\hline Total time on ART, per additional month & $<1.0$ & 0.794 & & \\
\hline Time on second line ART, per additional month & $<1.0$ & 0.154 & 1 & 0.921 \\
\hline Time on ATV/r, per additional month & $<1.0$ & 0.706 & 0.9 & 0.409 \\
\hline \multicolumn{5}{|l|}{ BMI $\left(\mathrm{kg} / \mathrm{m}^{2}\right)$} \\
\hline normal & Referent & & & \\
\hline underweight & 1.5 & 0.525 & 0.4 & 0.235 \\
\hline overweight/obese & 0.4 & 0.034 & 0.3 & 0.026 \\
\hline
\end{tabular}

Current boosted protease inhibitor

$\mathrm{ATV} / \mathrm{r}$

Referent

$L P V / r$

Current NRTI backbone

$\begin{array}{lll}\text { TDF/3TC } & \text { Referent } & \\ \text { AZT/3TC } & <1.0 & 0.942 \\ \text { ABC/3TC } & 2.5 & 0.429 \\ \text { d4T/3TC } & 1 & \end{array}$

CD4 cell count (cells $/ \mathrm{mm}^{3}$ )
$\geq 100$
Referent

$<100$

Pill count adherence

good $(95 \%-105 \%)$

poor $(<95 \%$ or $>105 \%)$

Total bilirubin, per unit rise $(\mathrm{mg} / \mathrm{dL})$

Total bilirubin level elevated $(>1.3 \mathrm{mg} / \mathrm{dL})$ normal $(\leq 1.3 \mathrm{mg} / \mathrm{dL})$
Referent

$\begin{array}{lll}0.9 & 0.804 & 0.7\end{array}$

0.4
$<0.001$

Referent 
versus ATV/r [30]. Improved access to second line ART in Malawi ([2], http://www.who.int/hiv/pub/guidelines/ arv2013/download/en/) also may potentially explain the improved virological outcomes evidenced in this study.

Objective biologic measures of ART adherence are more reliable in predicting poor adherence and VF than pill count or patient's self-report, which often over-estimate adherence levels [29, 31-35]. Therefore, our finding that normal bilirubin values in the setting of ATV/r-based therapy better predicted treatment failure than pill count is not surprising and supports the use of bilirubin as a surrogate for ATV/r adherence and response [36]. Both the lower mean bilirubin and the 2.3 times increased risk for virologically failing patients highlights the usefulness of this test in monitoring second line treatment failure. Patients treated with ATV/r have an increase in unconjugated and total bilirubin levels due to the concentrationdependent ATV/r inhibition of the enzyme uridine diphosphate glucuronosyltransferase 1A1 (UGT1A1) responsible for bilirubin conjugation [17-19]. Despite transient fluctuations of serum bilirubin levels over time, the elevation often remains stable for at least two years after initiation of ATV/r [36] making it useful for adherence monitoring in ART-experienced patients [20, 37]. In countries using ATV/r based second line therapy, a costeffective algorithm incorporating targeted bilirubin and drug resistance testing into routine VL monitoring could be developed to monitor second line VF and promote treatment switch. In that algorithm, patients with poor adherence based on low bilirubin levels are targeted for intensive adherence counseling and support. Among those with elevated bilirubin and hence presumed good adherence, in addition to standard adherence counseling, drug resistance assays would be conducted to detect potential drug resistance. Only those failing treatment due to resistance mutations would switch to third line ART. As resistance testing and third line ART are relatively expensive, such an algorithm would address adherence issues, target those most likely to have resistance, and more promptly identify those with resistance in need of third line treatment. This strategy may potentially yield good virological outcomes [38] and increase survival rates [39, 40] in this target population. As fewer samples for resistance testing would be taken from patients failing second line ART simply due to poor adherence, this would increase the proportion of samples with significant resistance mutations where an effective third line treatment regimen would need to be determined.

Lower CD4 cell count was significantly associated with VF in this study. A previous study conducted within Malawi's national ART program had indicated an association of lower CD4 cell count $(<100$ cells $/ \mathrm{ml})$ with high levels of first line ART resistance, possibly contributing to second line ART failure [41]. However, studies in other resource- limited settings have demonstrated poor positive predictive values of WHO CD4 cell count criteria $(<100$ cells $/ \mathrm{ml})$ for virological failure, with the potential for unnecessary ART switch [42-45]. Adults aged 25-40 years old, being majority among those failing therapy in these facilities, independently predicted VF thus supporting findings from other studies [46]. These individuals are more likely to miss clinic appointments and hence less likely to be adherent to ART [47]. Similarly, increasing age may be associated with greater maturity and understanding of health issues, and established lifestyles. These factors may likely influence health-seeking behaviors, long-term adherence to ART and virological suppression. We may not have seen a significant relationship in adolescents aged 1524 years old due to small sample size of this age group. Body mass index (BMI) frequently used for monitoring clinical progression of HIV/AIDS demonstrated an association with VF. Low BMI has been linked with HIVassociated morbidity and mortality [2], whereas weight gain while on ART may indicate optimal medication adherence. Despite varied views on the use of clinical markers to predict VF $[48,49]$, high BMI (overweight and obesity) was significantly associated with VL $\leq 1000$, perhaps relating the general health improvements with favorable ART response in this population. However, the large proportion of second line ART patients classified as overweight or obese in this study may pose future health concern due to non-communicable diseases. Gender was not independently associated with VF in spite of the perceived vulnerabilities of men to ART failure [50-52]. Similarly, the duration of second-line ART was not associated with VF [2], probably reflecting the high genetic barrier to viral resistance accorded by protease inhibitors in the context of good adherence [53].

The findings of this study should be considered in light of their strengths and limitations. Firstly, there is the likelihood of selection bias. Only participants receiving second line ART and who presented to the clinic during the period of the study were included for analysis. Those missing visits, and hence at higher risk for VF due to poor adherence to clinic appointments and missed doses, were not included for the analysis. Therefore, our results represent VF rates among persons on second line ART retained in care and may underestimate the true rate of treatment failure. Secondly, this analysis was based on cross-sectional observational data thereby limiting our ability to determine a causal relationship between laboratory parameters used to monitor second-line ART adherence and VF. Similarly, baseline values which would have improved our understanding of the factors associated with VF by looking at the temporal associations of clinical and laboratory parameters with second line ART, were unavailable. However, because LH and MPC outpatient HIV clinics are major public providers of second line ART in Malawi's capital city of 
Lilongwe, the findings in this study could be generalizable for ART programs in Malawi and other regions with a generalized HIV epidemic in urban populations. Thirdly, pill count adherence may be misleading particularly in treatment-experienced patients in whom social desirability bias may encourage pill dumping and lead to overestimation of medication adherence $(>105 \%)$. Pill count adherence was overestimated in 73 (49.7\%) of those with poor pill count adherence estimates. However, just like suboptimal pill count adherence ( $<95 \%)$, overestimation of adherence has been associated with increased risk of VF [54] thus justifying their inclusion as poor pill count adherence measurements in this analysis. Fourthly, many of the participants were highly experienced on second line ART (42 months) but had much shorter exposure to ATV/r (9 months) due to Malawi's recent adoption of ATV/r in second line ART regimens. Therefore, we are unable to comment on whether our results would be similar for those with longer duration of $\mathrm{ATV} / \mathrm{r}$ exposure and if there were transient fluctuations of serum bilirubin over time [36]. Lastly, genotypic resistance testing that is important when selecting alternative therapeutic regimens [55] was not available to characterize the resistance profiles of those with VF, although development of resistance to PIs is uncommon [9]. Resistance testing would have allowed more thorough evaluation of the associations between virological failure, ATV/r adherence and bilirubin levels.

\section{Conclusions}

Given the limited access to VL monitoring, drug resistance testing and third line treatment regimens in subSaharan Africa, strategies for cost-effective delivery of ART services are needed. Bilirubin, as a surrogate marker for ATV/r adherence among patients receiving second line therapy, better predicted VF than pill count adherence. Strategic use of bilirubin and VL testing to target adherence counseling and support may be cost-effective in monitoring second line ART adherence and VF particularly for adults aged $25-40$ years and those with CD4 cell count $<100$ cells $/ \mathrm{mm}^{3}$. Therefore, individuals with normal or low bilirubin levels and VF (VL $>1000$ copies/ml) while on ATV/r-based second line ART would benefit from intensive adherence counseling and support to help optimize the duration of second line treatment regimens. Drug resistance testing targeted for patients with virological failure despite persistently elevated bilirubin levels would facilitate timely switch to third line antiretroviral regimens whenever available.

\section{Abbreviations}

ABC/3TC: Abacavir/Lamivudine; aOR: adjusted Odds Ratio; ART: Antiretroviral therapy; ATV/r: Atazanavir/ritonavir; AZT/3TC: Zidovudine/Lamivudine; BMI: Body Mass Index; CBC: Complete Blood Count; EMR: Electronic Medical Record; LH: Lighthouse; LPV/r: Lopinavir/ritonavir; MPC: Martin Preuss Center; NLR: Negative Likelihood Ratio; NPV: Negative Predictive Value;

NRTI: Nucleoside reverse transcriptase inhibitor; NVP: Nevirapine; PI/r: Boosted
Protease Inhibitor; PLHIV: People Living with HIV; PLR: Positive Likelihood Ratio; PPV: Positive Predictive Value; TB: Tuberculosis; TDF/3TC/EFV: Tenofovir/ Lamivudine/Efavirenz; VF: Virological Failure; VL: Viral load;

\section{Acknowledgements}

The authors would like to thank the University of North Carolina Project laboratory staff and Lighthouse Trust clinics staff for assisting with the data collection for the study. Similarly, we would like to thank Lighthouse Trust Monitoring and Evaluation department for their diligence in data extraction from the EMR systems. We would also like to thank all the study participants who were on second line ART at LH and MPC during the study period for their willingness to participate in the study.

\section{Funding}

This project was supported by the National Institutes of Health Office of the Director, Fogarty International Center through the Fogarty Global Health Fellows Program Consortium comprised of the University of North Carolina, John Hopkins University, Morehouse School of Medicine and Tulane University (1R25TW009340-01), and by the Doris Duke Charitable Foundation International Scholars Program. The funders had no role in the study design, data collection and analysis, decision to publish, or preparation of the manuscript.

\section{Availability of data and materials}

Data supporting the findings can be found in the Tables. Data extracted from the electronic medical records at Lighthouse Trust clinics in Lilongwe, Malawi is property of the Ministry of Health and may be shared upon request.

\section{Authors' contributions}

$\mathrm{DO}, \mathrm{RL}, \mathrm{RB}, \mathrm{CS}, \mathrm{TH}, \mathrm{SP}$ and $\mathrm{MH}$ conceptualized and designed the study. DO, $\mathrm{RL}, \mathrm{HT}, \mathrm{PT}, \mathrm{SG}, \mathrm{CCS}, \mathrm{MN}$ and RB acquired and analyzed the data. All authors participated in the interpretation of data analyses, critical review and revision of the manuscript. All authors have read and approved the final manuscript. The content is solely the responsibility of the authors and does not necessarily represent the official views of the funding agencies.

\section{Competing interests}

The authors declare that they have no competing interests.

\section{Ethics approval and consent to participate}

This study was a component of programme evaluation of Lighthouse Trust operations and was approved by the Malawi National Health Sciences Research Committee (NHSRC) and the Biomedical Institutional Review Board of the University of North Carolina at Chapel Hill, United States. According to these two review boards, retrospective reviews of existing programmatic data are exempt from formal consenting procedures. All data collected were de-identified prior to analysis.

\section{Consent to publish}

Not applicable.

\section{Publisher's Note}

Springer Nature remains neutral with regard to jurisdictional claims in published maps and institutional affiliations.

\section{Author details}

${ }^{1}$ Tulane University School of Public Health and Tropical Medicine, New Orleans, USA. ${ }^{2}$ Tufts University School of Medicine, Boston, USA. ${ }^{3}$ Lighthouse Trust, Lilongwe, Malawi. ${ }^{4}$ The International Union Against Tuberculosis and Lung Disease, Paris, France. ${ }^{5}$ University of North Carolina Project, Lilongwe, Malawi. ${ }^{6}$ University of North Carolina School of Medicine, Chapel Hill, USA. ${ }^{7}$ Department of Public Health, University of Malawi, College of Medicine, School of Public Health and Family Medicine, Lilongwe, Malawi. 
Received: 7 March 2017 Accepted: 6 June 2017 Published online: 03 July 2017

\section{References}

1. Keiser $O$, Tweya $H$, Braitstein P, Dabis F, MacPhail P, Boulle A, et al. ART-LINC of leDEA Study Group: Mortality after failure of antiretroviral therapy in subSaharan Africa. Trop Med Int Health. 2010:15(2):251-8.

2. Hosseinipour MC, Kumwenda JJ, Weigel R, Brown LB, Mzinganjira D, Mhango B, Eron JJ, Phiri S, van Oosterhout JJ: Second-line treatment in the Malawi antiretroviral programme: high early mortality, but good outcomes in survivors, despite extensive drug resistance at baseline HIV Med 2010, 11(8):510-518

3. Harries AD, Zachariah R, van Oosterhout JJ, Reid SD, Hosseinipour MC, Arendt $\mathrm{V}$, et al. Diagnosis and management of antiretroviral-therapy failure in resource-limited settings in sub-Saharan Africa: challenges and perspectives. The Lancet Infectious Diseases. 2010;10(1):60-5.

4. Boyd M, Emery S, Cooper DA. Antiretroviral roll-out: the problem of secondline therapy. The Lancet. 2009;374(9685):185-6.

5. Keiser O, Chi BH, Gsponer T, Boulle A, Orrell C, Phiri S, et al. leDEA Southern Africa Collaboration: Outcomes of antiretroviral treatment in programmes with and without routine viral load monitoring in Southern Africa. AIDS. 2011;25(14):1761-9.

6. Ramadhani HO, Bartlett JA, Thielman NM, Pence BW, Kimani SM, Maro VP, Mwako MS, Masaki LJ, Mmbando CE, Minja MG, Lirhunde ES, Miller WC: Association of first-line and second-line antiretroviral therapy adherence Open Forum Infect Dis 2014, 1(2):ofu079.

7. Johnston V, Fielding K, Charalambous S, Mampho M, Churchyard G, Phillips $A$, et al. Second-line antiretroviral therapy in a workplace and communitybased treatment programme in South Africa: determinants of virological outcome. PLoS One. 2012;7(5):e36997.

8. Ekstrand ML, Shet A, Chandy S, Singh G, Shamsundar R, Madhavan V, et al. Suboptimal adherence associated with virological failure and resistance mutations to first-line highly active antiretroviral therapy (HAART) in Bangalore, India. Int Health. 2011;3(1):27-34.

9. Levison JH, Orrell C, Gallien S, Kuritzkes DR, Fu N, Losina E, et al. Virologic failure of protease inhibitor-based second-line antiretroviral therapy without resistance in a large HIV treatment program in South Africa. PLoS One. 2012;7(3):e32144.

10. Ajose O, Mookerjee S, Mills E, Boulle A, Ford N. Treatment outcomes of patients on second-line antiretroviral therapy in resource-limited settings: a systematic review and meta-analysis. AIDS. 2012;26(8):929-38.

11. Khan S, Das M, Andries A, Deshpande A, Mansoor H, Saranchuk P, et al. Second-line failure and first experience with third-line antiretroviral therapy in Mumbai. India Glob Health Action. 2014;7:24861.

12. Chakravarty J, Sundar S, Chourasia A, Singh PN, Kurle S, Tripathy SP, et al. Outcome of patients on second line antiretroviral therapy under programmatic condition in India. BMC Infect Dis. 2015;15:517-015-1270-8.

13. Hosseinipour MC, Gupta RK, Van Zyl G, Eron JJ, Nachega JB. Emergence of HIV drug resistance during first- and second-line antiretroviral therapy in resource-limited settings. J Infect Dis. 2013;207(Suppl 2):S49-56.

14. Orrell C, Harling G, Lawn SD, Kaplan R, McNally M, Bekker LG, et al. Conservation of first-line antiretroviral treatment regimen where therapeutic options are limited. Antivir Ther. 2007;12(1):83-8.

15. Wilson D, Keiluhu AK, Kogrum S, Reid T, Seriratana N, Ford N, et al. HIV-1 viral load monitoring: an opportunity to reinforce treatment adherence in a resource-limited setting in Thailand. Trans $\mathrm{R}$ Soc Trop Med Hyg. 2009;103(6):601-6.

16. Ministry of Health. Malawi Guidelines for Clinical Management of HIV in Children and Adults: second edition ed. Lilongwe, Malawi: Ministry of Health; 2014.

17. Zhang D, Chando T, Everett D, Patten C, Dehal S, Humphreys WG. In vitro inhibition of UDP glucuronosyltransferases by atazanavir and other HIV protease inhibitors and the relationship of this property to in vivo bilirubin glucuronidation. Drug Metab Dispos. 2005;33(11):1729-39.

18. Smith D, Jeganathan S, Ray J. Atazanavir plasma concentrations vary significantly between patients and correlate with increased serum bilirubin concentrations. HIV Clin Trials. 2006;7(1):34-8.

19. Cleijsen RMM, Van de Ende, M E, Kroon FP, Lunel FV, Koopmans PP, Gras L de wolf F, burger DM: therapeutic drug monitoring of the HIV protease inhibitor atazanavir in clinical practice. J Antimicrob Chemother 2007, 60(4): 897-900.
20. Barrios A, Rendón A, Gallego O, Martín Carbonero L, Valer L, Ríos P, et al Predictors of virological response to atazanavir in protease inhibitorexperienced patients. HIV Clin Trials. 2004;5(4):201-5.

21. Laprise C, Baril JG, Dufresne S, Trottier H. Atazanavir and other determinants of hyperbilirubinemia in a cohort of 1150 HIV-positive patients: results from 9 years of follow-up. AIDS Patient Care STDs. 2013;27(7):378-86.

22. Petersen K, Riddle M, Jones L, Furtek K, Christensen A, Tasker S, et al. Use of bilirubin as a marker of adherence to atazanavir-based antiretroviral therapy. AIDS. 2005;19(15):1700-2.

23. Douglas G, Gadabu O, Joukes S, Mumba S, McKay M, Ben Smith A, et al. Using touchscreen electronic medical record systems to support and monitor national scale-up of antiretroviral therapy in Malawi. PLoS Med. 2010:7(8).

24. Paterson DL. Adherence to Protease Inhibitor Therapy and Outcomes in Patients with HIV Infection. Ann Intern Med. 2000;133(1):21.

25. Pujades Rodríguez M, Balkan S, Arnould L, Brinkhof MAW, Calmy A. Treatment failure and mortality factors in patients receiving second-line HIV therapy in resource-limited countries. JAMA. 2010;304(3):303-12.

26. Rupérez M, Pou C, Maculuve S, Cedeño S, Luis L, Rodríguez J, et al. Determinants of virological failure and antiretroviral drug resistance in Mozambique. J Antimicrob Chemother. 2015;70(9):2639-47.

27. Fox MP, Cutsem GV, Giddy J, Maskew M, Keiser O, Prozesky H, et al. leDEASA collaboration: Rates and predictors of failure of first-line antiretroviral therapy and switch to second-line ART in South Africa. J Acquir Immune Defic Syndr. 2012;60(4):428-37.

28. Maggiolo F, Ravasio L, Ripamonti D, Gregis G, Quinzan G, Arici C, et al. Similar Adherence Rates Favor Different Virologic Outcomes for Patients Treated with Nonnucleoside Analogues or Protease Inhibitors. Clinical Infectious Diseases. 2005;40(1):158-63.

29. van Zyl GU, van Mens TE, Mcllleron H, Zeier M, Nachega JB, Decloedt E, et al. Low lopinavir plasma or hair concentrations explain second-line protease inhibitor failures in a resource-limited setting. J Acquir Immune Defic Syndr. 2011;56(4):333-9.

30. Akanmu AS, Adeyemo T, Lesi F, Bello FO, Okwuegbuna K, Oloko K, et al. Immunological and Virological Outcomes of Patients Switched from LPV/r to ATV/r-Containing Second- Line Regimens. Curr HIV Res. 2015;13(3):176-83.

31. Duong M, Piroth L, Peytavin G, Forte F, Kohli E, Grappin M, et al. Value of patient self-report and plasma human immunodeficiency virus protease inhibitor level as markers of adherence to antiretroviral therapy: relationship to virologic response. Clin Infect Dis. 2001:33(3):386-92.

32. Gandhi M, Ameli N, Bacchetti P, Anastos K, Gange SJ, Minkoff H, et al. Atazanavir concentration in hair is the strongest predictor of outcomes on antiretroviral therapy. Clin Infect Dis. 2011;52(10):1267-75.

33. Haberer JE, Kiwanuka J, Nansera D, Ragland K, Mellins C, Bangsberg DR. Multiple measures reveal antiretroviral adherence successes and challenges in HIV-infected Ugandan children. PLoS One. 2012;7(5):e36737.

34. Haberer JE, Cook A, Walker AS, Ngambi M, Ferrier A, Mulenga V, Kityo C, Thomason M, Kabamba D, Chintu C, Gibb DM, Bangsberg DR: Excellent adherence to antiretrovirals in HIV+ Zambian children is compromised by disrupted routine, HIV nondisclosure, and paradoxical income effects PLOS One 2011, 6(4):e18505.

35. Liu H, Golin CE, Miller LG, Hays RD, Beck CK, Sanandaji S, et al. A comparison study of multiple measures of adherence to HIV protease inhibitors. Ann Intern Med. 2001;134(10):968-77.

36. Morello J, Alvarez E, Cuenca L, Vispo E, González Lahoz J, Soriano V, et al. Short communication: use of serum bilirubin levels as surrogate marker of early virological response to atazanavir-based antiretroviral therapy. AIDS Res Hum Retrovir. 2011;27(10):1043-5.

37. Rekic D, Clewe O, Röshammar D, Flamholc L, Sönnerborg A, Ormaasen V, et al. Bilirubin-a potential marker of drug exposure in atazanavir-based antiretroviral therapy. AAPS J. 2011;13(4):598-605.

38. Win MM, Maek-A-Nantawat W, Phonrat B, Kiertiburanakul S, Sungkanuparph S. Virologic and Immunologic Outcomes of the Second-Line Regimens of Antiretroviral Therapy Among HIV-Infected Patients in Thailand. J Int Assoc Physicians AIDS Care (Chic). 2011;10(1):57-63.

39. Lorenzana SB, Hughes MD, Grinsztejn B, Collier AC, Luz PM, Freedberg KA, et al. Genotype assays and third-line ART in resource-limited settings: a simulation and cost-effectiveness analysis of a planned clinical trial. AIDS. 2012;26(9):1083-93.

40. Harrigan PR, Rhee S, Jordan MR, Raizes E, Chua A, Parkin N, Kantor R, Van Zyl GU, Mukui I, Hosseinipour MC, Frenkel LM, Ndembi N, Hamers RL, Rinke 
de Wit TF, Wallis CL, Gupta RK, Fokam J, Zeh C, Schapiro JM, Carmona S, Katzenstein D, Tang M, Aghokeng AF, De Oliveira T, Wensing AMJ, Gallant JE, Wainberg MA, Richman DD, Fitzgibbon JE, Schito M, Bertagnolio S, Yang C, Shafer RW: HIV-1 Drug Resistance Mutations: Potential Applications for Point-of-Care Genotypic Resistance Testing PLOS ONE 2015, 10(12): e0145772.

41. Hosseinipour MC, van Oosterhout JJ, Weigel R, Phiri S, Kamwendo D, Parkin $\mathrm{N}$, et al. The public health approach to identify antiretroviral therapy failure: high-level nucleoside reverse transcriptase inhibitor resistance among Malawians failing first-line antiretroviral therapy. AIDS. 2009;23(9):1127-34.

42. Oosterhout V, Joep JG, Brown L, Weigel R, Kumwenda J, Mzinganjira D, et al. Diagnosis of antiretroviral therapy failure in Malawi: poor performance of clinical and immunological WHO criteria. Tropical Med Int Health. 2009; 14(8):856-61.

43. Keiser O, MacPhail P, Boulle A, Wood R, Schechter M, Dabis F, et al. ARTLINC Collaboration of the International Databases to Evaluate AIDS (leDEA): Accuracy of WHO CD4 cell count criteria for virological failure of antiretroviral therapy. Trop Med Int Health. 2009;14(10):1220-5.

44. Moore DM, Awor A, Downing R, Kaplan J, Montaner JSG, Hancock J, et al. CD4+ T-Cell Count Monitoring Does Not Accurately Identify HIV-Infected Adults With Virologic Failure Receiving Antiretroviral Therapy. JAIDS J Acquired Immune Defic Syndromes. 2008:49(5):477-84.

45. Mee P, Fielding K, Charalambous S, Churchyard G, Grant A. Evaluation of the WHO criteria for antiretroviral treatment failure among adults in South Africa. AIDS. 2008;22(15):1971-7.

46. Khienprasit N, Chaiwarith R, Sirisanthana T, Supparatpinyo K. Incidence and risk factors of antiretroviral treatment failure in treatment-naïve HIV-infected patients at Chiang Mai University Hospital, Thailand. AIDS Research and Therapy. 2011;8(1):42.

47. Glass TR, De Geest S, Weber R, Vernazza PL, Rickenbach M, Furrer $H$, et al. Correlates of self-reported nonadherence to antiretroviral therapy in HIVinfected patients: the Swiss HIV Cohort Study. J Acquir Immune Defic Syndr. 2006:41(3):385-92.

48. Vanobberghen FM, Kilama B, Wringe A, Ramadhani A, Zaba B, Mmbando D, Todd J: Immunological failure of first-line and switch to second-line antiretroviral therapy among HIV-infected persons in Tanzania: analysis of routinely collected national data Tropical Medicine \& International Health 2015; 2015, 20(7):880-892.

49. Anglaret X. Anthropometric and immunological success of antiretroviral therapy and prediction of virological success in west African adults. Bull World Health Organ. 2008;2008(6):435-42.

50. Boulle C, Kouanfack C, Laborde-Balen G, Boyer S, Aghokeng AF, Carrieri MP, Kaze S, Dontsop M, Mben JM, Koulla-Shiro S, Peytavin G, Spire B, Delaporte E, Laurent C, Stratall ANRS 12110ESTHER Study Group: Gender Differences in Adherence and Response to Antiretroviral Treatment in the Stratall Trial in Rural District Hospitals in Cameroon J Acquir Immune Defic Syndr 2015, 69(3):355-364.

51. Jones LR, Moretti F, Calvo AY, Dilernia DA, Manrique JM, Gomez-Carrillo M, et al. Drug resistance mutations in HIV pol sequences from Argentinean patients under antiretroviral treatment: subtype, gender, and age issues. AIDS Res Hum Retroviruses. 2012;28(8):949-55.

52. Penot P, Hema A, Bado G, Kabore F, Sore I, Sombie D, et al. The vulnerability of men to virologic failure during antiretroviral therapy in a public routine clinic in Burkina Faso. J Int AIDS Soc. 2014;17:18646.

53. Levison J, Orrell C, Gallien S, Kuritzkes D, Fu N, Losina E, et al. Virologic failure of protease inhibitor-based second-line antiretroviral therapy without resistance in a large HIV treatment program in South Africa. PLoS One. 2012;7(3):e32144.

54. Okatch H, Beiter K, Eby J, Chapman J, Marukutira T, Tshume O, et al. Brief Report: Apparent Antiretroviral Overadherence by Pill Count is Associated With HIV Treatment Failure in Adolescents. J Acquir Immune Defic Syndr. 2016;72(5):542-5.

55. Durant J, Clevenbergh P, Halfon P, Delgiudice P, Porsin S, Simonet P, Montagne N, Boucher CA, Schapiro JM, Dellamonica P: Drug-resistance genotyping in HIV-1 therapy: the VIRADAPT randomised controlled trial Lancet 1999, 353(9171):2195-2199.

\section{Submit your next manuscript to BioMed Central and we will help you at every step:}

- We accept pre-submission inquiries

- Our selector tool helps you to find the most relevant journal

- We provide round the clock customer support

- Convenient online submission

- Thorough peer review

- Inclusion in PubMed and all major indexing services

- Maximum visibility for your research

Submit your manuscript at www.biomedcentral.com/submit 